\title{
Lipopolysaccharide inhibits or accelerates biomedical titanium corrosion depending on environmental acidity
}

\author{
Fei Yu ${ }^{1}$, Owen Addison ${ }^{2}$, Stephen J Baker ${ }^{3}$ and Alison J Davenport ${ }^{1}$
}

Titanium and its alloys are routinely used as biomedical implants and are usually considered to be corrosion resistant under physiological conditions. However, during inflammation, chemical modifications of the peri-implant environment including acidification occur. In addition certain biomolecules including lipopolysaccharide (LPS), a component of Gram-negative bacterial cell walls and driver of inflammation have been shown to interact strongly with Ti and modify its corrosion resistance. Gram-negative microbes are abundant in biofilms which form on dental implants. The objective was to investigate the influence of LPS on the corrosion properties of relevant biomedical Ti substrates as a function of environmental acidity. Inductively coupled plasma mass spectrometry was used to quantify Ti dissolution following immersion testing in physiological saline for three common biomedical grades of Ti (ASTM Grade 2, Grade 4 and Grade 5). Complementary electrochemical tests including anodic and cathodic polarisation experiments and potentiostatic measurements were also conducted. All three Ti alloys were observed to behave similarly and ion release was sensitive to $\mathrm{pH}$ of the immersion solution. However, LPS significantly inhibited Ti release under the most acidic conditions (pH 2), which may develop in localized corrosion sites, but promoted dissolution at pH 4-7, which would be more commonly encountered physiologically. The observed pattern of sensitivity to environmental acidity of the effect of LPS on Ti corrosion has not previously been reported. LPS is found extensively on the surfaces of skin and mucosal penetrating $\mathrm{Ti}$ implants and the findings are therefore relevant when considering the chemical stability of Ti implant surfaces in vivo.

International Journal of Oral Science (2015) 7, 179-186; doi:10.1038/ijos.2014.76; published 30 January 2015

Keywords: corrosion; electrochemistry; inductively coupled plasma mass spectrometry; lipopolysaccharide; titanium

\section{INTRODUCTION}

Titanium (Ti) and Ti alloys are routinely used for biomedical applications such as dental implants and bone anchorage of extra-oral prostheses and devices. Ti and its alloys are employed because of their perceived biocompatibility, suitable mechanical properties and corrosion resistance. ${ }^{1}$ The favourable cellular and bimolecular responses to $\mathrm{Ti}$ that are reported are conferred by the presence on the Ti surface of a thin passive oxide film which provides chemical stability. ${ }^{1-3}$ It has been established in in vitro experiments that $\mathrm{Ti}$ and its biomedical alloys are highly resistant to pitting corrosion and crevice corrosion at temperatures below $65{ }^{\circ} \mathrm{C} .{ }^{4-6}$ Therefore, corrosion of Ti leading to the release of particles and ions into surrounding tissues is rarely considered by surgeons and patients as a likely event.

However, corrosion-related failures of implanted $\mathrm{Ti}$ devices and prostheses have been regularly reported within the medical literature $^{7-8}$ and Ti corrosion products have been detected in significant quantities in the tissues and fluids adjacent to implants that have not been subjected to obvious tribological processes. ${ }^{9-11}$ In addition, using mass spectrometry, investigators have also shown that Ti levels can be significantly elevated in compartments remote from the implant site such as the serum of patients with indwelling Ti fixation devices. ${ }^{12}$ Characterisation of the systemically distributed Ti has demonstrated ionic associations with native biomolecules rather than a presence in particulate form which further supports that corrosion processes have been operative. $^{12}$

The biological consequences of the release of Ti corrosion products and accumulation in tissues are significant, with pain, ${ }^{8}$ changes in the peri-implant tissue phenotype ${ }^{13}$ genotoxicity ${ }^{14}$ and chronic inflammation leading to osteolysis and implant loss, ${ }^{15}$ being reported. The release of Ti under physiological conditions can be accounted for by both mechanically assisted crevice corrosion and biologically mediated processes. However, to date, our mechanistic understanding of the processes remains incomplete. ${ }^{7-8,16}$

The physiological environment into which a Ti implant is placed varies with site and with the device application, but is always a complex system containing various inorganic and organic components such as ions, amino acids, proteins and fatty acids, as well as living cells. The specific composition of this environment can also change in either health or disease due to physiological processes ${ }^{9}$ or as a direct consequence of the deterioration of the implant itself. ${ }^{8}$ Physiological fluids are buffered solutions and normally the $\mathrm{pH}$ remains close to 7. ${ }^{17}$ It has been demonstrated that in the presence of inflammation and/or in conditions associated with mechanically assisted crevice corrosion, the physiological environment can become locally acidi-

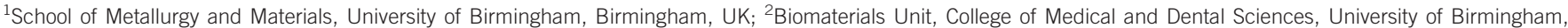
Birmingham, UK and ${ }^{3}$ School of Geography Earth and Environmental Sciences, University of Birmingham, Birmingham, UK

Correspondence: Dr O Addison, Biomaterials Unit, College of Medical and Dental Sciences, University of Birmingham, Birmingham B4 6NN, UK

E-mail: o.addison@bham.ac.uk

Accepted 24 November 2014 
fied. ${ }^{16}$ Measurement of fluids in contact with Ti alloy orthopaedic implants retrieved during revision surgery has shown that the local acidity can reach as low as $\mathrm{pH} 2.5 .^{8}$ For implants that become associated with a microbial biofilm such as dental implants, the presence of acidogenic bacteria has been shown to be capable of reducing the local $\mathrm{pH}$ to below 4.5 over sustained periods of time. ${ }^{18-19}$

It is evident that acidic environments can be generated in the body and are a potential hazard for metallic implants. More recently, there has been a focus on the contribution that organic molecules can have in altering the corrosion resistance of biomedical alloys in vivo. For a number of organic molecules relevant to the peri-implant environment the data reported have been inconsistent and it remains uncertain as to what effects they may have on the corrosion resistance of Ti and other biomedical alloys. ${ }^{20-24}$ It is, however, well known that many of these organic molecules strongly adsorb onto implant surfaces (including Ti and its alloys) and therefore, their potential role in modifying corrosion resistance is clinically relevant.

One organic molecule, lipopolysaccharide (LPS) also known as endotoxin, has received considerable attention because of its abundance and its crucial role as a mediator in peri-implant inflammation. ${ }^{25-27}$ Significant levels of adherent LPS are present on Ti implant surfaces ${ }^{27}$ and as LPS is a constituent of the cell wall of Gram-negative bacteria, any implant with a bioflim is likely to be associated with elevated LPS in the immediate environment. Although the effect of acidity on Ti corrosion is well reported, the influence of LPS has received much less attention and the results reported to date are incomplete. ${ }^{25,28-29}$ Using electrochemical impedance spectroscopy and cyclic polarisation curves, it has been reported that the corrosion of ASTM Grade 2 commercially pure (CP) Ti was increased in LPS containing media. ${ }^{25}$ However, in the reported electrochemical impedance spectroscopy results, the polarisation resistance $\left(R_{\mathrm{p}}\right)$ of Ti in the presence of LPS was increased when compared with that in the absence of LPS, indicating a lower corrosion rate ${ }^{30}$ and therefore the results appear to be inconsistent. The objective of the current study was to investigate the influence of LPS on the corrosion properties of relevant biomedical Ti substrates as a function of environmental acidity. Given the inconclusive data that have been previously reported, the null hypothesis that there is no impact of LPS on the corrosion resistance biomedical Ti was tested.

\section{MATERIALS AND METHODS}

\section{Ti sample preparation}

Commercial purity ASTM Grade $2 \mathrm{Ti}$ (lower Fe content, CP-Ti-G2); commercial purity ASTM Grade 4 Ti (higher Fe content, CP-Ti-G4) and ASTM Grade $5 \mathrm{Ti}$ (Ti6Al4V) were sourced (Titanium Products Ltd, Solihull, UK-all grades of Ti were cold-rolled and annealed at 600-700 ${ }^{\circ} \mathrm{C}$ for $20 \mathrm{~min}$ (Grades 2 and 4) or $1 \mathrm{~h}$ (Grade 5)) and compositional analysis acquired (Table 1 ). Nominally identical disc-shaped specimens of CP-Ti-G2 and CP-Ti-G4 $(14 \mathrm{~mm}$ diameter and $1 \mathrm{~mm}$ thickness) were machined by the supplier. The surfaces were subsequently ground to a consistent finish using sequential grades of $\mathrm{SiC}$ abrasive paper from P400, through P800, P1200 and P2400 to P4000 grit with deionized water as a lubricant. The surfaces of Ti6Al4V discshaped specimens (14 mm diameter and $1.2 \mathrm{~mm}$ thickness) were prepared using abrasive cloths MD-Piano (Struers, Ballerup, Denmark) and deionized water as a lubricant followed by MD-Largo (Struers) with a $9 \mu \mathrm{m}$ diamond suspension as a lubricant (Struers). Finally all three grades of $\mathrm{Ti}$ were polished with a MD-Chem polishing cloth (Struers) using OP-S Colloidal Silica suspension (Struers) to produce a consistent mirror finish on both sides. All samples were thoroughly cleaned sequentially in acetone, ethanol, and deionized water using ultrasonic agitation for $10 \mathrm{~min}$ at each stage. Specimens were finally dried in a nitrogen stream and used in further experiments.

\section{Immersion testing}

Physiological saline $(0.9 \% \mathrm{NaCl})$ was used as a representative immersion medium (ASTM F1801-97(2009)e1), enabling comparison of findings with similar studies. ${ }^{16,28-29}$ It also avoids the use of $\mathrm{P}$, which causes potential polyatomic interferences in inductively coupled plasma mass spectrometry (ICP-MS) measurements on solutions containing $\mathrm{Ti}^{31}$ Each solution was modified according to two experimental factors, $\mathrm{pH}$ (at four levels) and LPS (with or without the addition of LPS). The $\mathrm{pH}$ value of the media was measured with a calibrated $\varnothing 40 \mathrm{pH}$ meter (Beckman Instruments, Brea, CA, USA) and modified to $\mathrm{pH} 7$, $5.5,4$ or 2 by adding lactic acid (Sigma-Aldrich, Dorset, UK). To investigate the effect of LPS, a further series of test solutions at each $\mathrm{pH}$ were prepared containing $150 \mu \mathrm{g} \cdot \mathrm{mL}^{-1}$ of LPS (Escherichia coli LPS 055:B5; Sigma-Aldrich, Dorset, UK) with the $\mathrm{pH}$ re-measured immediately after LPS addition. To minimize contamination with elements of interest for subsequent mass spectrometry measurements, ultrapure water (Gibco, Life Technologies, Paisley, UK) and mass spectrometry grade reagents were used throughout.

All prepared Ti samples were immersed in $2 \mathrm{~mL}$ of test solution in a $30 \mathrm{~mL}$ container sealed to prevent evaporation. For each experimental condition, three samples of each Ti grade (CP-Ti-G2, CP-Ti-G4 and Ti6Al4V) were immersed and incubated at $37{ }^{\circ} \mathrm{C}$. The samples were consistently positioned so that the periphery of each disc made multiple point contacts with the radius of the container but allowed the majority of the surface area to be exposed to the immersion medium. Samples were gently agitated on an A500 orbital mixer (Thermo Denley, Colchester, UK) for $1 \mathrm{~h}$ per day. For each sample, the test media was retrieved and replaced with new solutions after 7 days. The $\mathrm{pH}$ values of the prepared test media were measured immediately before use on each occasion. Following 4 weeks of immersion, the retrieved media for each sample were pooled together to form $8 \mathrm{~mL}$, which was used for ICP-MS measurement. Prior to the ICP-MS measurement, the $\mathrm{pH}$ values of all the collected immersion solutions were re-measured again to identify any modification in acidity over the immersion period. The exposed surface area of Grade 5 disc shaped specimens was $\sim 2 \%$ greater than Grade 2 and 4 specimens, and this was taken into account in the interpretation of the ICP-MS data.

Table 1 The composition of CP-Ti-G2, CP-Ti-G4 (manufacturers compositional certificate, weight-\%) and Ti6AI4V (ASTM standard F110897A, weight-\%)

\begin{tabular}{|c|c|c|c|c|c|c|c|c|c|}
\hline Substrate & $\mathrm{N}$ & C & $\mathrm{H}$ & $\mathrm{Fe}$ & 0 & Residual & $\mathrm{Al}$ & V & $\mathrm{Ti}$ \\
\hline CP-Ti-G2 & $<0.01$ & 0.01 & 0.02 & 0.03 & 0.11 & $<0.1 \%$ & & & Bal. \\
\hline CP-Ti-G4 & 0.006 & 0.007 & 0.002 & 0.22 & 0.30 & $<0.1 \%$ & & & Bal. \\
\hline Ti6Al4V & Max. 0.05 & Max. 0.1 & Max. 0.015 & Max. 0.3 & Max. 0.2 & & $5.5-6.75$ & $3.5-4.5$ & Bal. \\
\hline
\end{tabular}

$\mathrm{CP}$, commercially pure; Max., maximum; Bal., Balance. 


\section{Determination of released ion concentration}

Test solutions from each sample were syringe-filtered (pore size: $0.45 \mu \mathrm{m}$ ) and refrigerated at $4{ }^{\circ} \mathrm{C}$ prior to ICP-MS measurement. Elemental Ti concentration in the immersion solutions was quantified using ICP-MS (Agilent 7500ce ICP-MS) where the detectable limit for Ti was $0.2 \mathrm{ng} \cdot \mathrm{mL}^{-1}$. Initially two-way analyses of variance (ANOVA) were used to identify significant differences between ICP-MS measurements $(\alpha=0.05)$ where the factors were Ti grade (at three levels) and $\mathrm{pH}$ (at four levels) with tests run independently for samples with and without LPS. Subsequently, further two-way ANOVAs were conducted for each Ti grade where the factors were LPS (at two levels) and $\mathrm{pH}$ (at four levels). Post-hoc Tukey's tests $(\alpha=0.05)$ were used to identify significant differences between individual groups.

\section{Surface characterisation}

The surfaces of the Ti discs were characterized before and after immersion testing to identify surface modifications. Scanning electron microscopy (SEM) was undertaken with a JEOL 7000 SEM (Jeol, Tokyo, Japan) using an accelerating voltage of $20 \mathrm{kV}$, a beam current of $\sim 70 \mu \mathrm{A}$, an original magnification of $\times 5000$ and using both secondary electron mode and backscatter electron mode. The elemental composition was analysed using energy dispersive X-ray spectroscopy (detector model: 7558; collecting window: ATW 2; acquisition time: $60 \mathrm{~s}$; quantification method: standardless; Oxford Instruments, Abingdon, UK).

\section{Electrochemical testing}

A standard three-electrode cell with reference electrode, counter electrode and working electrode was used in a potentiostat (ACM Instruments, Cumbria, UK). The counter electrode was a Pt mesh and the reference electrode was a commercial saturated calomel electrode (SCE). All potentials are quoted against this reference scale. Ti discs were mounted in VARI-SET cold mounting acrylic (MetPrep, Coventry, UK) and used as the working electrode. The electrode was polished to a mirror surface using identical sample preparation methods as detailed previously for immersion studies.
Anodic and cathodic polarisation curves were measured separately. Freshly polished CP-Ti-G4 and Ti6Al4V electrodes were immersed in physiological saline media (that was adjusted to either $\mathrm{pH} 2$ or $\mathrm{pH} 4$ with lactic acid according to the protocol described above, with or without the addition of LPS). The open circuit potential (OCP) was measured for $1 \mathrm{~h}$ to allow growth of the passive oxide film on the metal surface. Anodic polarisation curves were measured by sweeping the potential from $-50 \mathrm{mV}$ below the OCP to $600 \mathrm{mV}$ (SCE), while cathodic polarisation curves were obtained by sweeping the potential from $50 \mathrm{mV}$ above OCP to $-900 \mathrm{mV}(\mathrm{SCE})$ at a sweep rate of $1 \mathrm{mV} \cdot \mathrm{s}^{-1}$. The polarisation curves were measured three times for each condition, using a fresh polished sample and solution in each case.

In addition, potentiostatic studies were performed to investigate the effect of the addition of LPS on the passive current density of CP-Ti-G4 and Ti6Al4V at pH 2 and pH 4. Freshly polished CP-Ti-G4 or Ti6Al4V discs were immersed in physiological saline which had been adjusted to $\mathrm{pH} 2$ or $\mathrm{pH} 4$, and a potential of $600 \mathrm{mV}$ (SCE) was applied. After 1000 seconds, LPS was added to create a concentration of $150 \mu \mathrm{g} \cdot \mathrm{mL}^{-1}$ of LPS in the immersion solution. Following the LPS addition, the solution was stirred continuously for $100 \mathrm{~s}$. To investigate the effects of agitation of the immersion solution on the passive current, the immersion solution was stirred again for $100 \mathrm{~s}$ following 1000 -s intervals on two separate occasions. The experiment was repeated twice for each $\mathrm{Ti}$ grade and each $\mathrm{pH}$ condition, using a fresh polished sample and solution in each case. Control experiments were conducted accordingly to an identical method with the exception of the addition of LPS.

\section{RESULTS}

\section{Quantification of Ti release}

Two-way ANOVAs demonstrated no significant effect of Ti grade on the magnitude of Ti release into physiological saline following immersion in LPS-free and LPS-containing media $(P>0.05)$, whereas $\mathrm{pH}$ significantly influenced the detected $\mathrm{Ti}$ elemental concentration $(P<0.01)$. Post-hoc Tukey's tests demonstrated that Ti release was significantly increased at $\mathrm{pH} 2$ for all $\mathrm{Ti}$ grades in comparison with $\mathrm{pH} \geqslant 4(P<0.01)$ (Figure 1 and Table 2$)$. Further Two-way

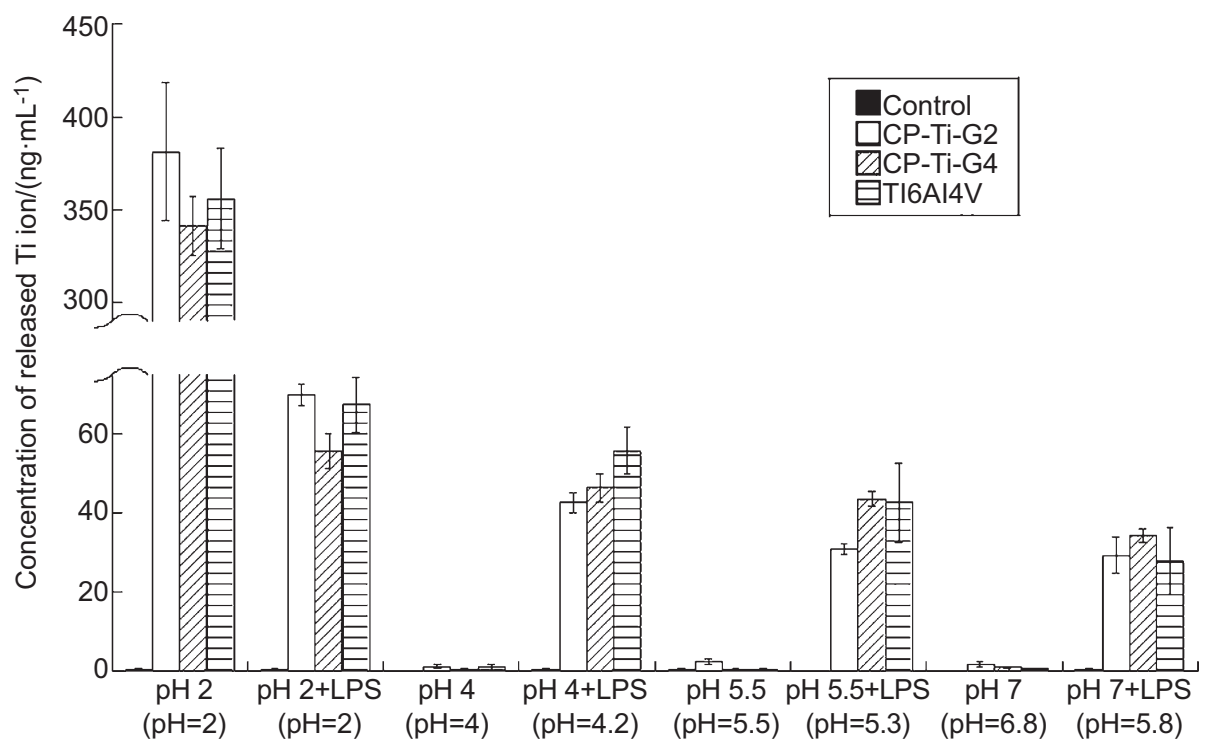

Figure 1 Mean concentrations of Ti ions released from mirror polished CP-Ti-G2, CP-Ti-G4 and Ti6AI4V following immersion in physiological saline with and without LPS for 4 weeks at $37{ }^{\circ} \mathrm{C}$. The final immersion solution $\mathrm{pH}$ values measured after the immersion period are provided below the initial values. Error bars refer to 1 standard deviation ( $n=3)$. CP, commercially pure; LPS, lipopolysaccharide. 
Table 2 Mean concentrations and standard deviations of Ti ions released from mirror polished CP-Ti-G2, CP-Ti-G4 and Ti6AI4V following immersion in physiological saline with and without LPS for 4 weeks at $37^{\circ} \mathrm{C}(n=3)$

\begin{tabular}{|c|c|c|c|c|}
\hline \multirow[b]{2}{*}{ Condition } & \multicolumn{4}{|c|}{ Mean concentrations \pm standard deviations $/\left(\mathrm{ng} \cdot \mathrm{mL}^{-1}\right)$} \\
\hline & Control group & CP-Ti-G2 group & CP-Ti-G4 group & Ti6Al4V group \\
\hline $\mathrm{pH} 2$ & $0.5 \pm 0.3$ & $381 \pm 37$ & $341 \pm 16$ & $356 \pm 27$ \\
\hline $\mathrm{pH} 2+\mathrm{LPS}$ & $0.4 \pm 0.3$ & $70 \pm 3$ & $56 \pm 4$ & $67 \pm 7$ \\
\hline $\mathrm{pH} 4$ & $0.2 \pm 0.01$ & $1 \pm 1$ & $0.5 \pm 0.01$ & $1 \pm 1$ \\
\hline $\mathrm{pH} 4+\mathrm{LPS}$ & $0.4 \pm 0.4$ & $43 \pm 2$ & $46 \pm 4$ & $56 \pm 6$ \\
\hline $\mathrm{pH} 5.5$ & $0.4 \pm 0.3$ & $3 \pm 1$ & $0.5 \pm 0.4$ & $0.4 \pm 0.2$ \\
\hline $\mathrm{pH} 5.5+\mathrm{LPS}$ & $<0.2$ & $31 \pm 1$ & $43 \pm 2$ & $43 \pm 10$ \\
\hline $\mathrm{pH} 7$ & $<0.2$ & $2 \pm 1$ & $1 \pm 0.2$ & $1 \pm 0.1$ \\
\hline $\mathrm{pH} 7+\mathrm{LPS}$ & $0.4 \pm 0.3$ & $29 \pm 5$ & $34 \pm 2$ & $28 \pm 9$ \\
\hline
\end{tabular}

$\mathrm{CP}$, commercially pure; LPS, lipopolysaccharide.

ANOVAs run independently for each Ti Grades, demonstrated that LPS significantly modified the mean Ti concentration quantified by ICP-MS of the immersion solution $(P<0.01)$. At $\mathrm{pH} 2$, the addition of LPS caused a significant decrease in the mean Ti concentration in the solution $(P<0.01)$, whereas for $\mathrm{pH}$ of $4,5.5$ and 7 , LPS addition significantly increased the detected levels of $\mathrm{Ti}(P<0.01)$ (Figure 1). Ti levels in the control immersion media with and without LPS were negligible. The action of LPS as a potential buffer was tested with $\mathrm{pH}$ measurements during immersion media preparation before and after LPS addition. $\mathrm{pH}$ was recorded again following the collection of the test solutions after the immersion period, prior to elemental quantification (Figure 1). A significant change in the $\mathrm{pH}$ of the media prepared at $\mathrm{pH} 7$ was observed following the immersion period where a reduction in $\mathrm{pH}$ to 5.8 was recorded. All remaining immersion solutions were not significantly affected (Figure 1).

\section{Anodic polarisation}

The anodic polarisation curves of polished Ti6Al4V and CP-Ti-G4 measured in physiological saline at $\mathrm{pH} 2$ and 4 in the absence and presence of LPS at $37{ }^{\circ} \mathrm{C}$ are shown in Figure 2. The values of OCP were
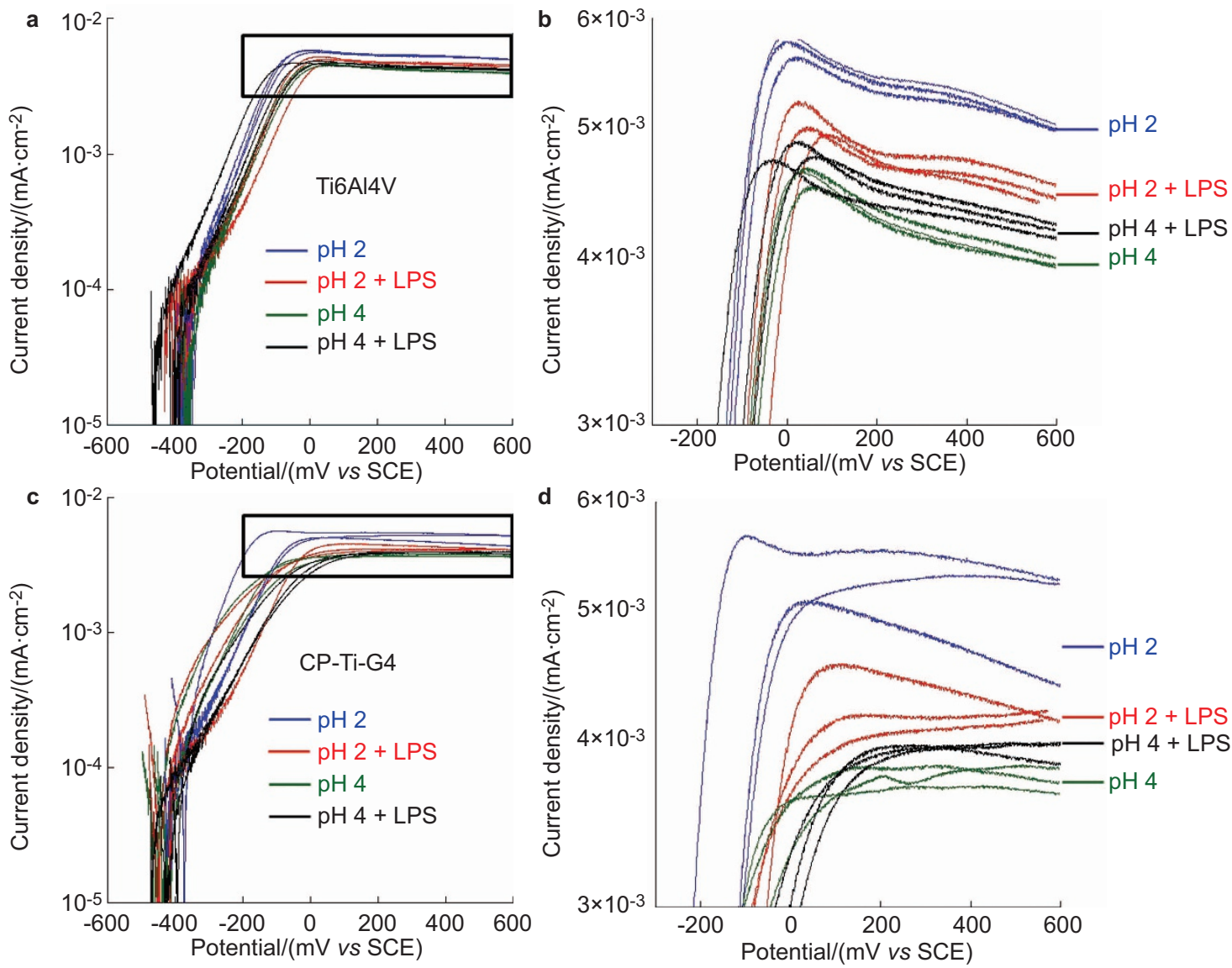

Figure 2 Anodic polarisation curves. (a) Ti6AI4V; (b) enlarged image of the region outlined in (a); (c) CP-Ti-G4; (d) enlarged image of the region outlined in (c). Ti6Al4V and $\mathrm{CP}-\mathrm{Ti}-\mathrm{G} 4$ in physiological saline solution adjusted to $\mathrm{pH} 2$ and $\mathrm{pH} 4$ in the absence and presence of $\mathrm{LPS}$ at $37{ }^{\circ} \mathrm{C}$ ( $n=3$-all data shown). CP, commercially pure; LPS, lipopolysaccharide. 

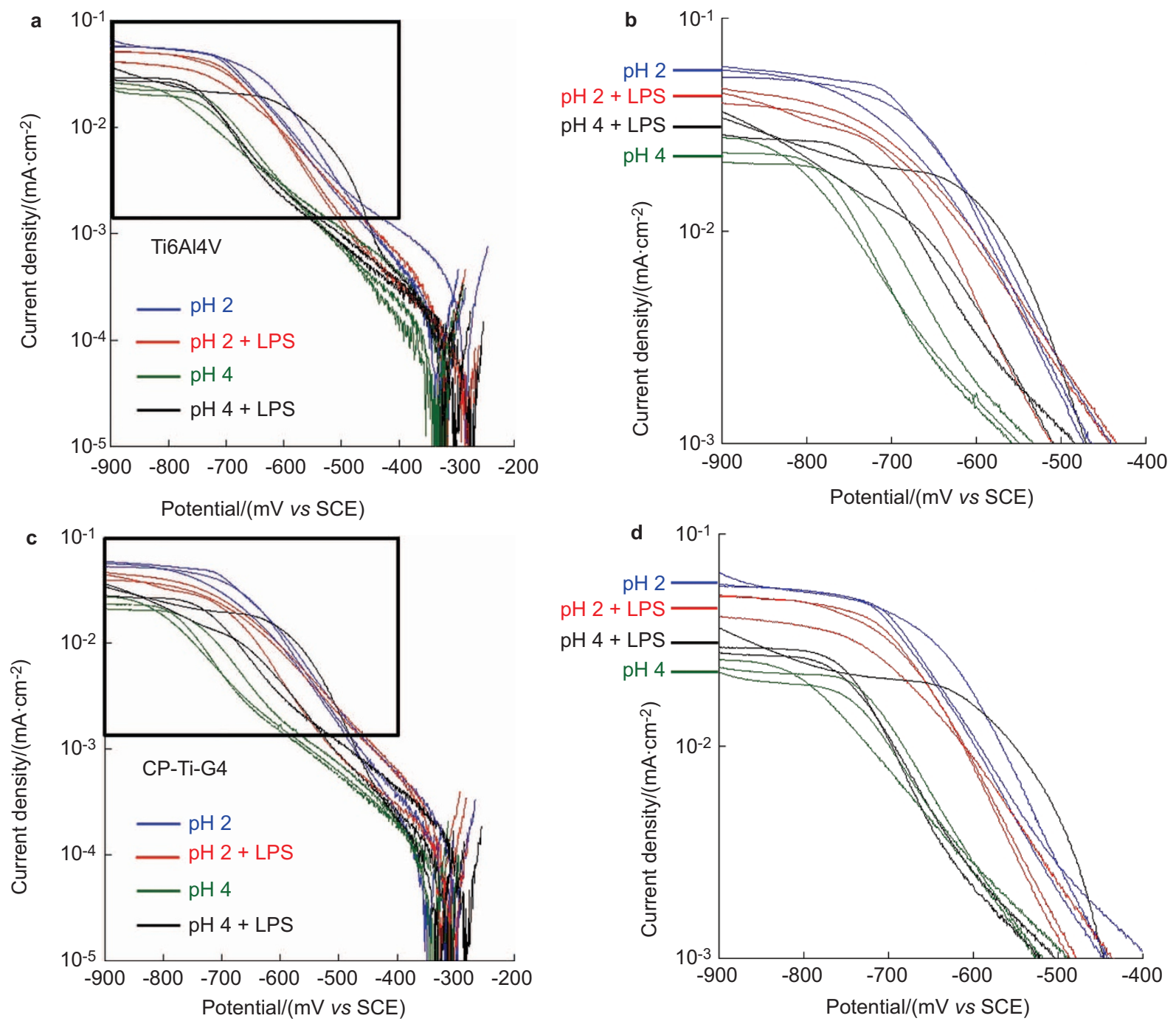

Figure 3 Cathodic polarisation curve. (a) Ti6Al4V; (b) enlarged image of the region outlined in (a); (c) CP-Ti-G4; (d) enlarged image of the region outlined in (c). Ti6AI4V and CP-Ti-G4 in physiological saline solution adjusted to pH 2 and pH 4 in the absence and presence of LPS at $37{ }^{\circ} \mathrm{C}$ ( $n=3$-all data shown). CP, commercially pure; LPS, lipopolysaccharide.

also listed in Table 3. A higher anodic current was measured for both Ti6Al4V and CP-Ti-G4 at pH 2 compared with measurements at $\mathrm{pH} 4$ (Figure 2). For media adjusted to $\mathrm{pH} 2$ containing LPS, the anodic current decreased for both Ti6Al4V and CP-Ti-G4 when compared with the LPS free physiological saline. In contrast at $\mathrm{pH} 4$, an increased anodic current was observed for both Ti6Al4V and CP-Ti-G4 in the LPS containing physiological saline when compared with the LPS-free media (Figure 2).

\section{Cathodic polarisation}

Cathodic polarisation curves of Ti6Al4V and CP-Ti-G4 were measured separately from the anodic measurements (Figure 3 ). A higher cathodic current was observed for Ti6Al4V and CP-Ti-G4 at pH 2 when compared to that at $\mathrm{pH} 4$ (Figure 3 ). In the presence of LPS, the cathodic current decreased for both Ti6Al4V and CP-Ti-G4 at pH 2, but slightly increased at $\mathrm{pH} 4$ when compared to the media without LPS.

\section{Potentiostatic study}

The potentiostatic measurements of polished Ti6Al4V and CP-Ti-G4 in physiological saline at $\mathrm{pH} 2$ and 4 with and without the addition of
LPS at $600 \mathrm{mV}(\mathrm{SCE})$ at $37^{\circ} \mathrm{C}$ are shown in Figure 4 . The solution was stirred at intervals to ensure mixing. LPS was added just prior to stirring at $\sim 1000 \mathrm{~s}$ for some of the measurements. It is clear that the passive current density of both grades of Ti is greater at $\mathrm{pH} 2$ than at $\mathrm{pH} 4$ (Figure 4). On addition of LPS, the current density measured for samples immersed at $\mathrm{pH} 2$ decreases rapidly (within $1000 \mathrm{~s}$ ) to the

Table 3 Mean OCP values and standard deviations of mirror polished CP-Ti-G4 and Ti6AI4V after $1 \mathrm{~h}$ immersion in physiological saline with and without LPS at $37{ }^{\circ} \mathrm{C}(n=6)$

\begin{tabular}{lcc}
\hline & \multicolumn{2}{c}{ Mean OCP values \pm standard deviations/(mV vs SCE) } \\
\cline { 2 - 3 } Condition & CP-Ti-G4 group & Ti6Al4V group \\
\hline $\mathrm{pH} 2$ & $-374 \pm 16$ & $-336 \pm 20$ \\
$\mathrm{pH} \mathrm{2+LPS}$ & $-390 \pm 33$ & $-355 \pm 17$ \\
$\mathrm{pH} \mathrm{4}$ & $-327 \pm 27$ & $-315 \pm 20$ \\
$\mathrm{pH} \mathrm{4+LPS}$ & $-394 \pm 55$ & $-378 \pm 30$ \\
\hline
\end{tabular}

CP, commercially pure; LPS, lipopolysaccharide; OCP, open circuit potential; SCE, saturated calomel electrode. 

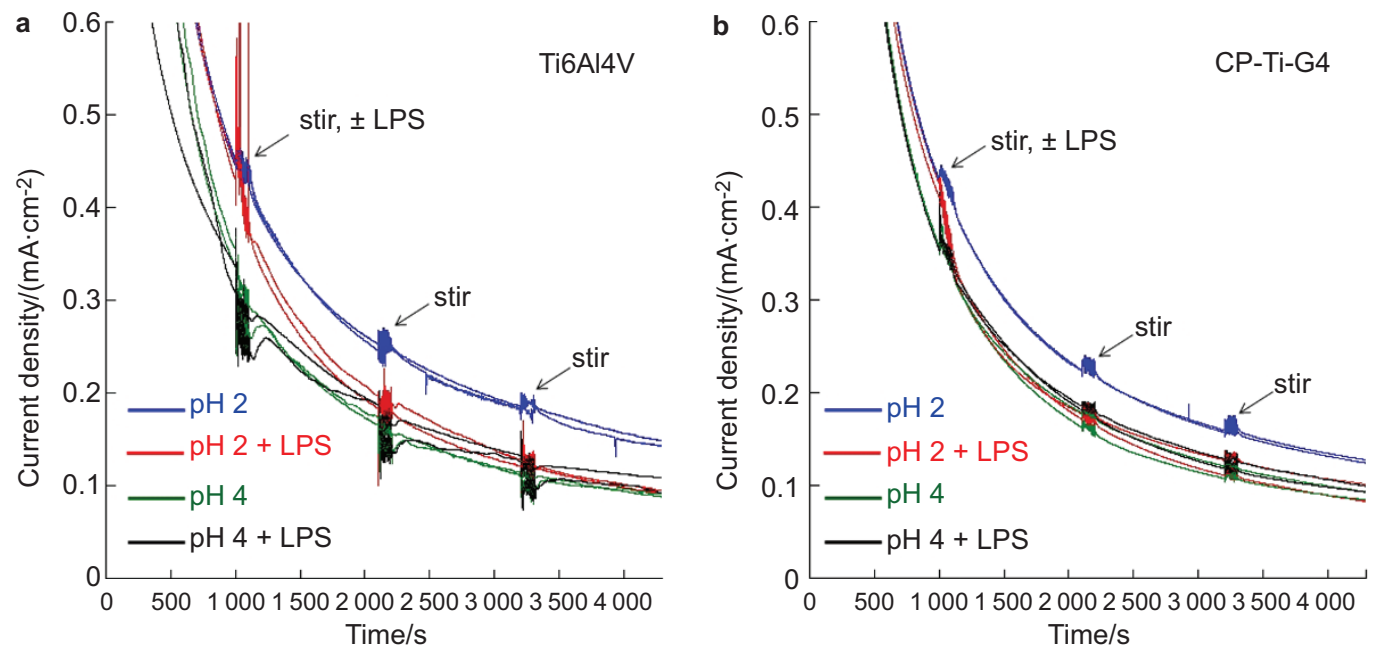

Figure 4 Potentiostatic study (600 mV vs SCE). (a) Ti6Al4V and (b) CP-Ti-G4 in physiological saline adjusted to pH 2 or pH 4 at $37{ }^{\circ} \mathrm{C}$; the solution was stirred for $\sim 100 \mathrm{~s}$ at $\sim 1000 \mathrm{~s}$ intervals to ensure mixing; for two experiments, LPS (in physiological saline) was added at $1000 \mathrm{~s}$ immediately before stirring to give a final concentration of $150 \mu \mathrm{g} \cdot \mathrm{mL}^{-1}$ ( $n=2$-all data shown). CP, commercially pure; LPS, lipopolysaccharide; SCE, saturated calomel electrode.

As polished
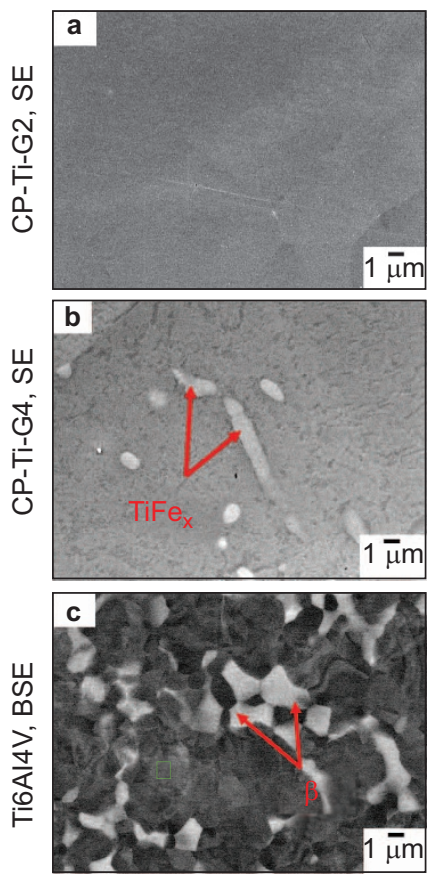

$\mathrm{PS} \mathrm{pH}=7$
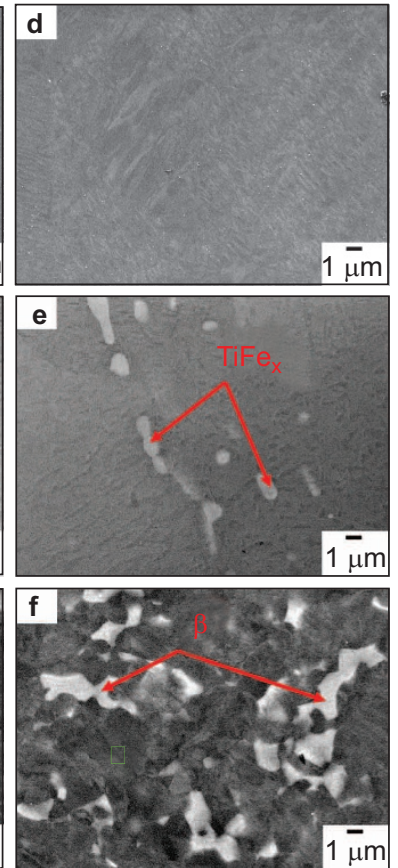

$\mathrm{PS} \mathrm{pH}=2$
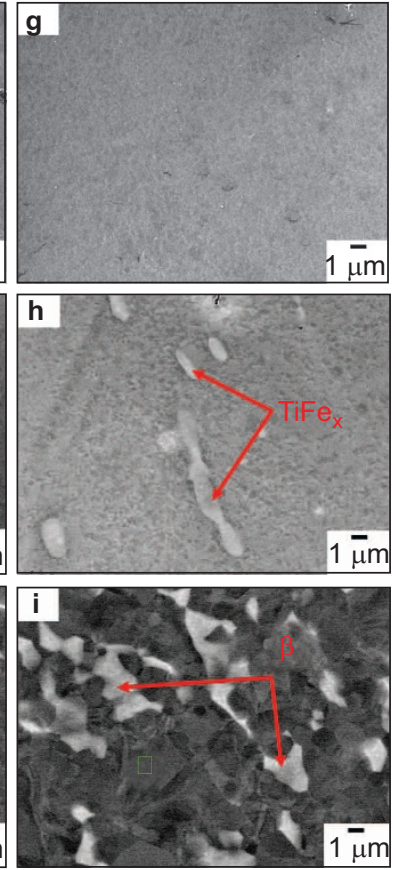

Figure 5 SEM images of mirror polished surfaces of Ti and its alloy. CP-Ti-G2, CP-Ti-G4 and Ti6Al4V before and after immersion for 4 weeks at $37{ }^{\circ} \mathrm{C}$ in physiological saline adjusted to $\mathrm{pH} 7$ or $\mathrm{pH}$ 2. BSE, backscatter electron mode SEM image; CP, commercially pure; PS, physiological saline; SE, secondary electron mode SEM image; SEM, scanning electron microscopy.

value found for samples immersed at $\mathrm{pH} 4$. However, LPS had no effect on the passive current density at $\mathrm{pH}$ 4. It should be noted that the addition of LPS had no detectable effect on the $\mathrm{pH}$ of the solution.

\section{Surface morphology and composition}

Figure 5 shows the surface morphology of all three alloys in the as polished condition, following immersion for 4 weeks in physiological saline at $\mathrm{pH} 7$ and $\mathrm{pH}$ 2. CP-Ti-G2 shows no significant second phase particles, whereas CP-Ti-G4 (higher Fe level) shows $\mathrm{TiFe}_{\mathrm{x}}$ intermetallic particles, and Ti6Al4V shows the characteristic two-phase $(\alpha / \beta)$ microstructure. No significant difference in the surface morphology before and after immersion was observed.

\section{DISCUSSION}

In the presence of inflammation, chemical modifications of the periimplant environment occur alongside changes in the cellular composition of the tissues. Local acidification and the presence of inorganic and organic species, which may modify the corrosion resistance of the implant itself, have been established. ${ }^{8-9,20}$ The current study demonstrated higher Ti ion release at $\mathrm{pH} 2$ compared with $\mathrm{pH} 4$ or 
7, consistent with previous work showing the observation of distinctly reduced ion release at and above $\mathrm{pH} 4 .^{3,28-29}$ However, the addition of LPS to the immersion solution significantly modified this pattern of Ti release, promoting corrosion at $\mathrm{pH} \geqslant 4$ but inhibiting it at $\mathrm{pH} 2, \mathrm{a}$ finding which has not previously been reported. The null hypothesis that there is no impact of LPS on the corrosion resistance biomedical Ti was therefore rejected. In addition, it has been previously demonstrated that the solubility of the Ti oxide surface layer is largely independent of acidity at $\mathrm{pH} \geqslant 4^{29}$ and therefore, the direct effect of LPS in lowering the solution $\mathrm{pH}$ is not considered to provide an explanation for the increased Ti release at $\mathrm{pH} \geqslant 4$.

Despite the differences in microstructure and composition between the three grades of $\mathrm{Ti}$ studied, no differences in $\mathrm{Ti}$ ion release were observed in the immersion conditions used, and accordingly, only CP-Ti-G4 (lower purity commercially pure Ti) and the alloy Ti6Al4V were studied in electrochemical tests. However, the presence of localized impurities (CP-Ti-G4) and intergranular zones (Ti6Al4V) is known to modify the morphology and potential rate of corrosion attack, and the current findings cannot exclude that differences would be observed with modified environmental conditions and measurement procedures.

The increased solubility of the passive oxide film on Ti alloys in highly acidic conditions was confirmed using anodic polarisation and potentiostatic measurements of CP-Ti-G4 and Ti6Al4V specimens. When the saline immersion solution was maintained at $\mathrm{pH} 2$, a shift towards both higher anodic currents, cathodic currents and passive currents was observed when compared with $\mathrm{pH} 4$ (Figures 2-4). Following addition of LPS to the $\mathrm{pH} 2$ solution, the anodic, cathodic and passive currents were all decreased (Figures 2-4). In contrast, addition of LPS to the $\mathrm{pH} 4$ solution increased the anodic and cathodic currents when compared with an LPS free environment (Figures 2 and 3). There was no significant change for the passive current at $\mathrm{pH} 4$ with and without the addition of LPS for both Ti6Al4V and CP-Ti-G4 (Figure 4).

It is generally established that organic molecules can affect the corrosion behaviour of metals mediated by adsorption onto the surfaces and/or chelation with the released dissolved ions. ${ }^{20-24}$ Studies on serum protein interactions with biomedical Ti surfaces, using potential sweep techniques, have established that surface adsorption processes are potential dependent. ${ }^{22}$ Further electrochemical tests have demonstrated that serum proteins such as albumin and fibrinogen can act to decrease the cathodic current, but also increase the anodic current. $^{20-21}$ These findings have been used to support a proposal that mechanistically, the protein has a covering and/or blocking effect. ${ }^{20}$

LPS are large molecules that are found in part of the outer membrane of Gram-negative bacteria and comprise of a lipid covalently bonded to a polysaccharide. LPS has been shown to have a high affinity for adsorption onto Ti surfaces, ${ }^{27}$ and in the current study, it is likely that LPS will rapidly adsorb onto the surface of the Ti samples following immersion. The observed decrease in corrosion at $\mathrm{pH} 2$ can be explained by the covering of potential reaction sites by the adsorbed molecule, which may further block ion release during the corrosion process. LPS has been shown to present different charges dependent on solution $\mathrm{pH}$ and in the current study, adsorption may have been promoted most at $\mathrm{pH} 2$ and least at neutral conditions. ${ }^{32}$ Furthermore, chain mobility, aggregation and the structure of LPS have been shown to be influenced by the presence of metal cations and $\mathrm{pH}$ and this may further act to modulate the anticipated surface adsorption and/or covering of reaction sites. ${ }^{33}$ However, this mechanism does not fully explain the enhanced corrosion found in the presence of LPS at $\mathrm{pH} \geqslant 4$ for the long-term immersion testing.
Although this has not been specifically demonstrated with Ti, LPS is understood to readily complex with metal cations at its polysaccharide component. ${ }^{34-35}$ It is possible that complexation of Ti ions in the surface of the passive film may enhance dissolution. However, this effect is smaller than the suppression of dissolution at $\mathrm{pH} \mathrm{2,} \mathrm{and} \mathrm{it}$ should be noted that addition of LPS did not increase the passive current density (expected if the passive film undergoes significant dissolution) in the short-term potentiostatic tests. The decrease in cathodic reactivity on addition of LPS at $\mathrm{pH} 2$ may again be associated with adsorption of LPS on $\mathrm{Ti}^{27}$ However, the apparent small increase in cathodic reactivity on addition of LPS at $\mathrm{pH} 4$ is more surprising. It is possible that complexation by LPS may lead to a thinner passive oxide film, with easier electron transfer for the cathodic reaction.

The environment of many Ti implants including dental implants and cranial anchorage devices will contain LPS due to the presence of Gram-negative bacteria in the surface biofilm. LPS has been shown to have a strong affinity for $\mathrm{Ti}$ and the current study demonstrates a significant decrease in $\mathrm{Ti}$ corrosion resistance at the mildly acidic and neutral $\mathrm{pH}$ levels, which will be commonly encountered in the peri-implant environment. Although an acknowledged extreme, $\mathrm{pH}$ measured in sites of mechanically assisted crevice corrosion (between modular components and in crevices) and locally in the microenvironment of the surface of acidogenic bacteria may be considerably lower approaching $\mathrm{pH} 2.5$. $^{8}$ Importantly, however, in the body, the electrochemical actions will take place through the biofilm developed on the implant surface and therefore, the observed behaviours may differ from the experimental outcome. Ti corrosion products have been demonstrated in the peri-implant tissues and the release of $\mathrm{Ti}$ ions and accumulation of Ti has been shown to be pro-inflammatory and have the potential to affect clinical outcomes. ${ }^{2,9,17}$

\section{CONCLUSIONS}

LPS is a component of the cell walls of Gram-negative bacteria, which may colonize the surfaces of Ti implants in the body. Under the experimental conditions of the current study, LPS inhibits corrosion of Ti (Grades 2, 4 and 5) in highly acidic environments representative of sites where mechanically assisted crevice corrosion may be occurring, whereas in slightly acidic and neutral environments, representative of sites of peri-implant inflammation LPS accelerates corrosion. Clinically, these findings are highly significant for skin and mucosa penetrating implants where the presence of a surface biofilm formation is implicit, suggesting that where the metal is exposed to a neutral $\mathrm{pH}$, LPS may cause a slight increase in the passive current density.

\section{ACKNOWLEDGEMENTS}

F Yu has been funded in part by the University of Birmingham and the China Scholarship Council. Dr O Addison is funded by NIHR Clinician Scientist Award NIHR/CS/010/001.

1 Liu XY, Chu PK, Ding CX. Surface modification of titanium, titanium alloys, and related materials for biomedical applications. Mater Sci Eng R 2004; 47(3/4): 49121.

2 Cadosch D, Chan E, Gautschi OP et al. Metal is not inert: role of metal ions released by biocorrosion in aseptic loosening — current concepts. J Biomed Mater Res A 2009; 91(4): 1252-1262.

3 Mabilleau G, Bourdon S, Joly-Guillou ML et al. Influence of fluoride, hydrogen peroxide and lactic acid on the corrosion resistance of commercially pure titanium. Acta Biomater 2006; 2(1): 121-129.

4 Virtanen S, Curty C. Metastable and stable pitting corrosion of titanium in halide solutions. Corrosion 2004; 60(7): 643-649.

$5 \mathrm{He} \mathrm{XH}$, Noel JJ, Shoesmith DW. Temperature dependence of crevice corrosion initiation on titanium grade-2. J Electrochem Soc 2002; 149(9): B440-B449. 
6 Yan L, Noel JJ, Shoesmith DW. Hydrogen absorption into Grade-2 titanium during crevice corrosion. Electrochim Acta 2011; 56(4): 1810-1822.

7 Thomas SR, Shukla D, Latham PD. Corrosion of cemented titanium femoral stems. J Bone Joint Surg Br 2004; 86(7): 974-978.

8 Hallam P, Haddad F, Cobb J. Pain in the well-fixed, aseptic titanium hip replacement. The role of corrosion. J Bone Joint Surg Br 2004; 86(1): 27-30.

9 Addison 0, Davenport AJ, Newport RJ et al. Do 'passive' medical titanium surfaces deteriorate in service in the absence of wear? J R Soc Interface 2012; 9(76): 31613164.

10 Uo M, Asakura K, Yokoyama A et al. X-ray absorption fine structure (XAFS) analysis of titanium-implanted soft tissue. Dent Mater J 2007; 26(2): 268-273.

11 Sarmiento-González A, Encinar JR, Marchante-Gayón JM et al. Titanium levels in the organs and blood of rats with a titanium implant, in the absence of wear, as determined by double-focusing ICP-MS. Anal Bioanal Chem 2009; 393(1): 335-343.

12 Nuevo-Ordóñez Y, Montes-Bayón M, Blanco-González E et al. Titanium release in serum of patients with different bone fixation implants and its interaction with serum biomolecules at physiological levels. Anal Bioanal Chem 2011; 401(9): 2747-2754.

13 Flatebø RS, Johannessen AC, Grønningsaeter AG et al. Host response to titanium dental implant placement evaluated in a human oral model. J Periodontol 2006; 77(7): 1201-1210.

14 Cadosch D, Al-Mushaiqri MS, Gautschi OP et al. Biocorrosion and uptake of titanium by human osteoclasts. J Biomed Mater Res A 2010; 95(4): 1004-1010.

15 Baldwin L, Hunt JA. Host inflammatory response to $\mathrm{NiCr}, \mathrm{CoCr}$, and $\mathrm{Ti}$ in a soft tissue implantation model. J Biomed Mater Res A 2006; 79(3): 574-581.

16 Virtanen S, Milosev I, Gomez-Barrena E et al. Special modes of corrosion under physiological and simulated physiological conditions. Acta Biomater 2008; 4(3): 468476.

17 Hanawa T. Metal ion release from metal implants. Mater Sci Eng C 2004; 24(6/7/8): $745-752$.

18 Souza JC, Ponthiaux P, Henriques M et al. Corrosion behaviour of titanium in the presence of Streptococcus mutans. J Dent 2013; 41(6): 528-534.

19 Koike $\mathrm{M}$, Fujii $\mathrm{H}$. The corrosion resistance of pure titanium in organic acids. Biomaterials 2001; 22(21): 2931-2936.

20 Cheng X, Roscoe SG. Corrosion behavior of titanium in the presence of calcium phosphate and serum proteins. Biomaterials 2005; 26(35): 7350-7356.

21 Jackson DR, Omanovic S, Roscoe SG. Electrochemical studies of the adsorption behavior of serum proteins on titanium. Langmuir 2000; 16(12): 5449-5457.

22 Contu F. The cathodic behavior of titanium: serum effect. J Biomed Mater Res Part B Appl Biomater 2012; 100(2): 544-552.
23 Padilla N, Bronson A. Electrochemical characterization of albumin protein on Ti-6Al$4 \mathrm{~V}$ alloy immersed in a simulated plasma solution. J Biomed Mater Res A 2007; 81(3): 531-543.

24 Contu F, Elsener B, Bohni $\mathrm{H}$. Serum effect on the electrochemical behaviour of titanium, Ti6A14V and Ti6Al7Nb alloys in sulphuric acid and sodium hydroxide. Corros Sci 2004; 46(9): 2241-2254.

25 Barão VA, Mathew MT, Assunção WG et al. The role of lipopolysaccharide on the electrochemical behavior of titanium. J Dent Res 2011; 90(5): 613-618.

26 Mathew MT, Barão VA, Yuan JC et al. What is the role of lipopolysaccharide on the tribocorrosive behavior of titanium? J Mech Behav Biomed Mater 2012; 8: 71-85.

27 Ragab AA, van de Motter R, Lavish SA et al. Measurement and removal of adherent endotoxin from titanium particles and implant surfaces. J Orthop Res 1999; 17(6): 803-809.

28 Strietzel R, Hösch A, Kalbfleisch $\mathrm{H}$ et al. In vitro corrosion of titanium. Biomaterials 1998; 19(16): 1495-1499.

29 Okazaki Y, Gotoh E. Comparison of metal release from various metallic biomaterials in vitro. Biomaterials 2005; 26(1): 11-21.

30 Pan J, Thierry D, Leygraf C. Electrochemical impedance spectroscopy study of the passive oxide film on titanium for implant application. Electrochim Acta 1996; 41(7/8): 1143-1153.

31 May TW, Wiedmeyer RH. A table of polyatomic interferences in ICP-MS. Atom Spectrosc 1998; 19(5): 150-155.

32 Schromm AB, Brandenburg K, Loppnow $\mathrm{H}$ et al. The charge of endotoxin molecules influences their conformation and IL-6-inducing capacity. J Immunol 1998; 161(10): 5464-5471

33 Garidel P, Rappolt M, Schromm AB et al. Divalent cations affect chain mobility and aggregate structure of lipopolysaccharide from Salmonella minnesota reflected in a decrease of its biological activity. Biochim Biophys Acta 2005; 1715(2): 122-131.

34 Sourek J, Tichý M, Levin J. Effects of certain cations (Fe, Zn, Mg, and Ca) on bacteria endotoxins. Infect Immun 1978; 21(2): 648-654.

35 Coughlin RT, Tonsager S, McGroarty EJ. Quantitation of metal cations bound to membranes and extracted lipopolysaccharide of Escherichia coli. Biochemistry 1983; 22(8): 2002-2007.

(1) (2) This work is licensed under a Creative Commons Attributioncc) $\mathrm{BY}$ NC SA NonCommercial-ShareAlike 3.0 Unported License. The images or other third party material in this article are included in the article's Creative Commons license, unless indicated otherwise in the credit line; if the material is not included under the Creative Commons license, users will need to obtain permission from the license holder to reproduce the material. To view a copy of this license, visit http://creativecommons.org/licenses/by-nc-sa/3.0/ 